\title{
Editorial
}

\section{Goals of Education: Protecting and Promoting Divergence and Sustainability}

Since the beginning of this century and even before that we have constantly been discussing what the goals of education for the new century should be (King \& Palmer, 2013; World Education Blog, 2014). This debate of new goals is still going on as we have almost approached the year 2015 - the final year of the Millennium Development Goals (MDG) and also of the goals of Education for All (EFA). These two groups of goals dominated the international development scenario in such a way that development in almost all developing countries revolved around these goals. As the present pattern of development games are going to continue and as there still are development givers and development receivers in the world, naturally then, we will have new goals and new targets for the period beyond 2015. Organizations like UN and the World Bank one day will declare new targets for adult literacy, for child mortality, for poverty reduction and so on and all developing countries will follow those goals and targets and all donors' donations revolve around those same goals and targets.

In this process of setting developmental goals and targets we have been ignoring many other important aspects that are vital to development. More importantly, we are ignoring to realize that we need to reengineer our development practices and this should begin with reunderstanding the meanings of development. The present practice of seeing development in the sense of modernization is not going to contribute to enhancing the life quality of millions of people around the world. This modernization based approach has been contributing towards homogenizing the world which is against the fundamental nature of the world. As we know the world is diverse, naturally as well as socio-culturally, obviously then, this homogenizing approach based on universal values is not going to work.

It is not that universal values are not important. They are of course important for understanding patterns and trends at a larger or macro scale but when it comes to the question of peoples at their locales in many parts of the world, local values are more meaningful. Universal values lack specificity and are less related to people and their worldviews in their everyday context and have made the whole process alien to them. Moreover, as we have been experiencing around the world such developmental values are based on the principle of maximization of consumption and exploitation which is not sustainable (Tilbury, 2003).

There is thus an urgent need to change the ways we have been following so far. This change demands not just some simple discrete moves but major shift in our approaches and practices. Therefore, there is a need for redefining the whole meaning of our education, 


\section{M. N. Parajuli}

development, and our values behind these processes. The paradigm shift is to be taken in moving from universal to localized values and needs as well as in realizing that there are multiple understandings regarding well-being and learning. The shift is now to be taken in moving from growth and material achievement to seeing these with the eyes of wisdom and values of protection and the shift is to be taken in going towards learning for wisdom, learning for humane thinking, and learning for humane living.

There are many other things that need some kinds of shift. In most developing countries developmental and educational activities began by rejecting local wisdom, knowledges and practices. This is because these local knowledges were perceived to be irrational and thus incapable for development; requiring external - Western - knowledge for support (Liz, 2014). More critically, along with the rejection of local knowledge base, the modernized development began by inculcating the minds of local people that they know nothing and are thus incapable of carrying out any developmental activities. This is why schooling and development practices carried out in developing countries are often centrally planned and implemented and thus hierarchic and structured. This is why in some parts of rural Nepal people say 'If you send your son to school he would be lost forever.' This is a very clear example of the fact how our present schooling has failed to contribute to rural transformation. Similarly, an excerpt from an old woman from a remote rural area in Nepal shows how locals are being rejected in the local development practices. "What an illiterate, low caste, poor, woman like me can do for the development of this village?" In her understanding, development is to be carried out by 'thulo manchhe' (big people) and she can have no role in this process. Besides, we can see how she was devaluing herself. This is the outcome of the past 60 plus years' developmental and educational practices.

This showed that we need to redefine what we mean by education. That is, we need to question: should we be continuing with the universal and modernized values of education that promoted "a mechanistic view of the natural environment as detached and wholly different from human nature; and a totalizing pedagogy that controls every moment and movement of students" (Arenas, 2007, p. 166)? As Arenas (2007) claims, these were all features that emerged during the seventeenth and eighteenth century and became an integral part of the ethos and organization of modern schooling.

This is where we need to change ourselves and look at our own local values and practices and humanize our science, our development and our education. Education should now mean promoting local knowledge and wisdom and promoting divergence. As noted above, diversity is the fundamental characteristics of the world. Locales of the world and the people living in those locales are privileged with natural and socio-cultural diversity - they are diverse in themselves and are diverse in comparison to others. This diversity gives them their own unique identity, knowledge and wisdom, values and worldviews, and heritage and opportunities. Hence, promoting divergence and honoring all cultures will be a pathway 
towards designing and practicing that education that will be promoting equity and social justice and development with sustainability. This in turn will eventually contribute to social transformation.

In order to go for such changes we need to de-formalize and reengineer our schooling. This means not only to promote non-formal education or making flexible arrangements in formal schools but to deconstruct the whole notion of formal schooling and moving towards promoting more localized systems of communities of learning and practices. With such an approach we take education to everyday life context and make it based upon local knowledge base, worldviews and practices and needs. The local knowledge systems are vital to maintain and promote uniqueness and diversities as well as cohesion and oneness of the given locale. Furthermore, the local knowledge systems can provide better strategies to address challenges and problems the local areas have been facing. The education that we practice should be able to respond to all external and internal challenges and opportunities present in a given time and context and this is possible only by practicing that system of knowing and educating that is open and flexible, goes on as a life-time process, and where there are no definite teachers and learners but all play active roles. That is, such practice recognizes skills, knowledge and wisdom people have and accepts that all, irrespective of their social positions - children, youths, and adults; women and men, poor and rich - have something to know and something to educate.

Such modes of knowing and educating derive from nature and nurture the nature because conservation and sustainability are behind the design philosophy of such practices. Such a practice not only teaches us for utilizing and preserving the available resources but also motivates to add on from our side (Parajuli, 2014). What is important is that such education derives from ecological thinking as against the economistic thinking of modernized education. Ecological thinking is making ourselves aware of our responsibilities towards the place and people we live in and with. This motivates us towards dialoguing and interacting with other peoples, cultures and nations and sharing the knowledge and heritage and thus prepares ourselves to be able to contribute toward social transformations in broader perspectives in the communities and nations where we live. All these are not possible from the present school systems that are largely globalized, marketized and standardized and are not much concerned with aspects like care, affection, and justice.

How can we then realize this need of de-formalizing schooling and adopt more open and flexible modes of knowing and educating? Is it possible to make a complete paradigm shift in our practices? Can we transform the present highly structured and centralized school or education system into flexible, plural and open systems? At the beginning this would look like simply not possible and even leading towards a chaotic situation. Modernized schooling and its set curriculum and textbooks, well defined learning outcomes and assessment system to measure the learning, periodized timing, disciplined relations, hierarchic management, etc. 
have already become directly and indirectly part of everyday life of not only of those who were/are schooled but also of those who were/are not schooled. In such a context, it is really difficult to think and envisage a completely different practice of knowing and educating going beyond the modern schooling of which most of us are so much habituated.

There is of course no definite answer to how de-formalizing the existing schooling is to be accomplished but it is clear that such change should lead to recognition of local modes of knowing and educating and develop these modes into loosely organized and well coordinated learning and sharing practices with enough open and flexible pathways and ladders and bridges. It is also important that such change process also borrow from the knowledge developed elsewhere because this would greatly facilitate the transformation process. Further, the change needs to be discussed, debated and deliberated so that the needs of all actors and communities could be addressed. It is important that all actors realize this need and be actively involved in this process. Such realization would lead to begin the process of knowing and educating as per the everyday needs of the people and communities eventually contributing to the process of social transformation (Sterling, 2008).

De-formalizing the schooling and its reengineering is essential to take it out from the control of the few. Schooling these days has remained a bureaucracy based structured system and thus it is essential that we de-bureaucratize it. If we really want to realize the goal of education as a right for all, we need to bring it to the civil space or to communities and people. To achieve this purpose, we need to reformulate the meaning, purpose, strategies, and approaches of education making it pluralistic, inclusive, just, and transformative. At the same time it is also necessary to redefine its linkages with other social processes and phenomena so that the process of knowing and educating could be directly linked to life quality and its sustainability of the people.

Inability to reengineer the schooling or the whole education practice would simply contribute to strengthening of hierarchies of privileges and continuation of reproduction of exclusion, inequality and injustice. Forces like marketization and globalization will be in full swing leading to gradual homogenization of human society in an unobstructed manner and disappearance of local cultures and values and knowledge base from the world. With such disappearance of diversities the world would lose all its meaning of being a vibrant world. Because it is only the local knowledge base - a synergetic product of socio-cultural world people have developed and the natural world where they live and prosper for a sustainable and resilient lifestyle - that can provide ways to cope with the challenges and utilize available opportunities. In absence of such synergetic knowledge, communities would not be able to cope with natural and socio-cultural hazards that have been growing and intensifying lately. All these could even cause risk to human survival and well being. 
In conclusion, it can be said that the discussion about the goals of education needs to be directed not only towards setting targets on providing access to schooling to all, improving their retention and increasing their learning achievements but also to assess whether the education today is capable of contributing to transform the lives of people. The discourse also needs to be directed towards what education is (Sterling, 2001) or to the question of whose education. Such discourse would provide a strong base for expanding the idea of education for sustainability, diversity, and resilience and eventually for social transformation.

\section{References}

Arenas, A. (2007). The intellectual development of modern schooling: An epistemological analysis. Universitas Humanistic, 64, 165-192. Retrieved from http://revistas.javeriana.edu.co/index.php/univhumanistica/article/view/2199/1448

King, K., \& Palmer, R. (2013). Post-2015 agendas: Northern tsunami, southern ripples? The case of education and skills. International Journal of Educational Development, 33(5), 409-425. doi:10.1016/j.ijedudev.2013.06.001

Liz, M. (2014). Inclusive education in Nepal: Assumptions and reality. Childhood. doi: $10.1177 / 0907568213514778$

Parajuli, P. (in press). Searching for Annapurna: Cultivating earthbound resilient abundance in the anthropocene epoch. In T. LeVasseur, P. Parajuli, \& N. Wirzba (Eds.), Sustainable agriculture and the world's religious traditions. Lexington, Kentucky: The University Press of Kentucky.

Sterling, S. (2008). Sustainable education: Towards a deep learning response to unsustainability. Policy \& Practice: A Development Education Review, 6, 63-68.

Sterling, S. (2001). Sustainable education - Re-visioning learning and change (Schumacher Society Briefing No. 6). Dartington, UK: Green Books.

Tilbury, D. (2003). Emerging issues in education for sustainable development. In B. Bhandari \& O. Abe (Eds.), Education for sustainable development in Nepal: Views and visions (pp. 29-40). Hayama, Japan: International Institute for Global Environmental Strategies (IGES).

World Education Blog. (2014, June 4). The Muscat agreement: New proposed post 2015 global education goal and targets announced today. Retrieved from http://efareport.wordpress.com/2014/06/04/the-muscat-agreement-new-proposed-post2015-global-education-goal-and-targets-announced-today/

Mahesh Nath Parajuli

School of Education, Kathmandu University mathesh@kusoed.edu.np 